\title{
OBSERVATORIO
}

\section{EN BUSCA DEL TIEMPO PERDIDO}

\author{
Lee Fontanella
}

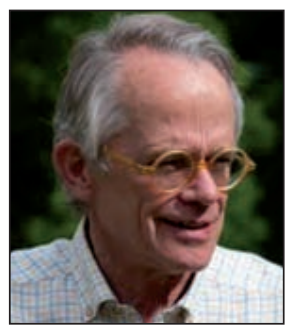

Lee Fontanella se doctoró en la Princeton University en 1971. Es autor de una docena de libros y un centenar de artículos y capítulos de libros sobre artes visuales y literatura hispánica. Ha sido comisario de varias exposiciones, y guionista de una película estrenada en 2007. Ha ejercido de profesor de literatura española, literatura comparada e historia de la fotografía en la University of Texas, Austin, durante 23 años; luego pasó a ser director de humanística y artes en Worcester, Massachusetts, durante 9 años. Actualmente está terminando de escribir un libro sobre fotografía antigua en España y un guión de cine, mientras sigue dando conferencias y participando en simposios.

894 Ocean Avenue New London, Connecticut 06320, EUA Tel.: +1-8607010697 Móv: +1-860 8849865

\section{Resumen}

Se ofrece una visión personal del trabajo del autor en archivos fotográficos desde su perspectiva de investigador en fotografía y como usuario de los fondos de varios países. Por su larga trayectoria en activo da cuenta de la evolución experimentada por las organizaciones que custodian el patrimonio fotográfico. Acota los inicios de los estudios sobre fotografía, las primeras revistas, y sobre todo trata los aspectos relacionados con la ordenación de los fondos según el uso que se hace por parte de diversos colectivos. Por un lado, señala que los orígenes de la atención a la fotografía se encuentran en el interés de los poderes en construir una historia propia, por lo que el tratamiento se enfoca hacia los temas o lugares locales y la fotografía actúa como auxiliar de la historia. Por otro, nos introduce en las necesidades del historiador de la fotografía, quien la estudia desde la vertiente artística, su autoría o su significado como objeto técnico. Relaciona las grandes colecciones museísticas en el mundo, donde los fondos se tratan de este último modo -más objetivado- y menciona algunas a las que asesoró -para los fondos "España", pero no españolas-, como experto sobre autores, hechos, contexto... Para el caso español, relata las dificultades que vivió para consultar los archivos hasta la llegada de la democracia y el nacimiento de la conciencia del valor de los fondos fotográficos públicos y privados. En definitiva, el autor aborda temas de interés técnico como el tratamiento, acceso y conservación de fondos, si bien lo hace desde el punto de vista de quien los ha utilizado y quien ha asesorado a las instituciones.

\section{Palabras clave}

Colecciones de fotografías, Archivos fotográficos, Criterios de ordenación de fondos, Necesidades del investigador, Estados Unidos, España, Historia de la fotografía.

\section{Title: In search of lost time}

\begin{abstract}
Personal impressions of working in photographic archives are presented here from the viewpoint of the researcher in photography, specifically one who has used these stores of material in several countries. The writer's many years of experience permits an assessment of the evolution undergone by institutions that house these materials. After noting the beginnings of studies in photographic history and the first periodical publications in this area, the analysis focuses on how materials are organized from the user's point of view. The early definition of photographic archives rested in organizations' interest in constructing their own histories, and therefore the archives were organized by local topics or sites. Photography was considered as auxiliary to history. On the other hand, the historian of photography has other needs in the study of photography from an artistic, biographic, or technical angle. Some of the world's great museum-quality collections are treated in this way -less subjectively- and several cases are described in which the author participated in their assessment and organization based on photographers, facts, or contexts that fell under the heading "Spain", although not always involving works by Spaniards, strictly speaking. The author also describes the experience of consulting photographic archives prior to and in the early years of democracy in Spain; later on, a surge of concern emerged in Spain for both public and private photographic collections. Finally, technical considerations such as the access to, treatment and conservation of archives are touched upon from the viewpoint of firsthand experience with institutional archives.
\end{abstract}




\section{Keywords}

Photographic collections, Photographic archives, Criteria for organizing archives, Researchers' needs, United States, Spain, History of photography.

Fontanella, Lee. "En busca del tiempo perdido". El profesional de la información, 2011, julio-agosto, v. 20, n. 4, pp. 365370.

http://dx.doi.org/10.3145/epi.2011.jul.01

\section{Introducción}

El título no tiene intención de robarle nada al gran Proust (i¿quién podría?!), sino de hacer recordar que el ir en busca de objetos perdidos en los archivos fotográficos casi siempre -no siempre- lleva la doble connotación de buscar lo representado y de buscar el objeto mismo ya trasladado al olvido. Dicho esto, desearía aclarar que cuando yo comencé a ir en busca de objetos parecidos en España y en otros países sobre el tema "España", me encontré con gran variedad de experiencias. Aunque la discrepancia entre esas experiencias ha disminuido muchísimo durante el tercio de siglo a que me refiero -lo que ha sido por el bien de España-, todavía queda. Las diferencias se deben a fundamentos históricos, psicológicos y culturales, y no sólo a medios tecnológicos.

Quisiera sentar además, antes de entrar más concretamente en materia, que nada de lo dicho indica que la España de hoy quede a la zaga respecto de otros países. Al contrario, por experiencia propia he de decir que España puede jactarse de ejemplos de mantenimiento de archivos fotográficos que son muy buenos, y no digo que perfectos, porque lógicamente no existe tal cosa.

España puede jactarse de ejemplos de mantenimiento de archivos fotográficos que son muy buenos por lo menos dos tentativas anteriores de venderla, según me contó hace años el mismo Helmut Gernsheim).

\section{Fundamentos de la ordenación}

La Pennsylvania State University no iba muy atrás en su interés, y llegó a hacerse cargo no sólo de archivos fotográficos, sino también de la dirección de la admirable publicación periódica History of photography (enero 1977), bajo la dirección del físico Heinz K. Henisch. Esta publicación, inimitable durante años, y otras por el estilo, como The Daguerreian annual (1990), tan dedicadas a la historia de la fotografía, apuntan a una observación que me atrevo a hacer: No he visto casi ningún caso de una ordenación de fondos concienzuda sin que a la vez se cultivara la historia de la fotografía como fenómeno tecnológico, económico-social, artístico. Es decir, sin que hubiera una paralela toma de conciencia por la historia de la fotografía. Por el contrario, sí que se han dado frecuentes casos de ordenación de fondos con el propósito de construir historias locales o regionales, y que por tanto obedecen intereses ajenos a la historia de la fotografía. Así pues, la formulación de historias de distintos fenómenos fotográficos ha fomentado unas consecuentes ordenaciones de fondos distintas $y$, sin duda, las dos publicaciones mencionadas han rendido semejante fruto.

En España, Nueva lente (1971), PhotoVisión (primavera de 1981), en parte Diorama (primavera 1984) y $40 / 50$ (1985), y Arte fotográfico desde décadas antes (1952) -aunque ésta

\section{Historia de la fotografía: los comienzos}

Es necesario encuadrar bien la presente discusión para que el lector no vaya a creer que por el hecho de que escriba un norteamericano -norteamericano que vivió dos años y medio en la España de la dictadura, desde 1961- presuma de que todo anduviese estupendamente en Norteamérica. De hecho, los centros donde se podía estudiar historia de la fotografía (ni hablar ya de cómo hacer crítica de la fotografía) acababan de institucionalizarse en el segundo lustro de los 60, y esto en contadísimos rincones académicos. La toma de conciencia, si mal no recuerdo, se manifestó en las universidades de Nuevo México y Princeton, y la de Texas había adquirido la gran colección Gernsheim (porque habían fracasado

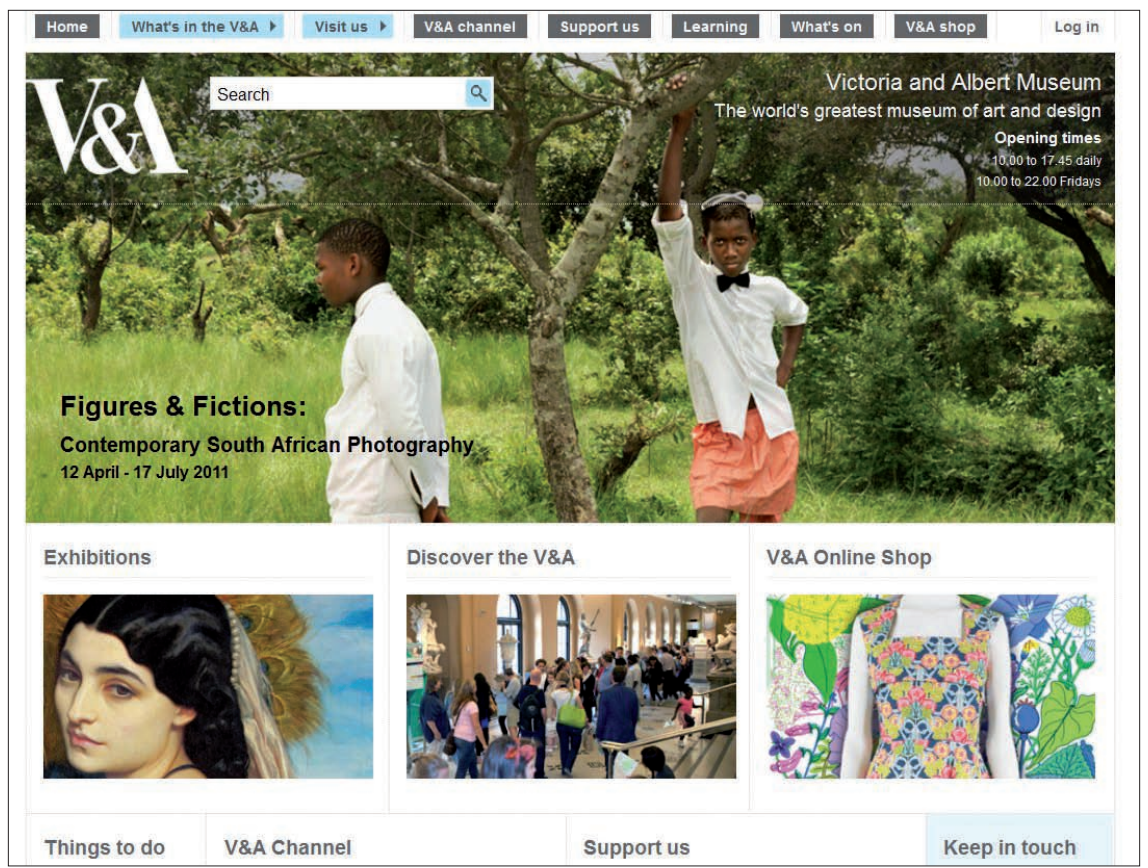

Victoria \& Albert Museum, http://www.vam.ac.uk 
notablemente dedicada a la práctica de la fotografía- entre otras publicaciones periódicas han hecho avanzar el interés en ordenar fondos, ya sean institucionales o privados.

\section{Interés por la historia}

Y, sin duda alguna, dentro de España el fenómeno que más que ningún otro ha movido la ordenación de fondos ha sido el interés que han mostrado los gobiernos autónomos por difundir sus historias visuales respectivas. De ahí la proliferación -en su mayor parte para bien- de historiadores locales y regionales y, además, la consecuente necesidad de ordenar archivos en los que trabajen más y mejor dichos historiadores, y de los que el gobierno pudiera sacar indicios de su propia existencia, por así decirlo, y de su propia razón histórica. Ejemplos por el estilo se han visto en Estados Unidos, pero ni en la proporción ni con la rapidez vistas en España. Es más, en Estados Unidos la edición de historias visuales locales no suele haber prestado atención a la historia de la fotografía por encima de la historia visual del lugar en cuestión. Esta práctica es notable sobre todo en los lugares que gozan de cierto "romance": el profundo sur del país -menos Florida-, el viejo oeste, el rincón noreste con sus aldeas y viejas tradiciones.

\section{Muchas revistas fotográficas han hecho avanzar el interés en ordenar fondos, ya sean institucionales o privados}

Esta tendencia hacia la utilización de la imagen visual para constituir historia propia no ha sido el motivo por el cual se han establecido la mayoría de las colecciones públicas conocidas en el mundo como propiamente museísticas (a diferencia de archivos históricos). Pecaré por omitir segu- ramente, pero pienso por ejemplo en el Victoria \& Albert Museum, el British Museum, la Royal Photographic Society que antes existía en Londres y luego en Bath, la colección almacenada en el castillo de Windsor, el Centre Canadien d'Architecture, Getty, la Société française de photographie, la colección de la Bibliothèque Nationale en París y la de la Biblioteca Nacional de España en Madrid, las colecciones de la New York Public Library y la Boston Public Library, la del Palacio Real en Madrid, o la de la Universidad de Texas ya mencionada.

La combinación de la historia propia, y de la fotografía como fenómeno artístico y tecnológico universal es muy saludable

En cambio, el enfoque a propósito en la historia nacional (notablemente la guerra civil norteamericana [1861-65]), por el que ha cobrado renombre la Library of Congress de Washington, representa otro punto de vista; uno más cercano, diría, aunque no el mismo, al de la fundación Fratelli Alinari en Florencia, sólo que ésta ha demostrado en un pasado bastante reciente una tendencia hacia la adquisición expansiva en lugar de un record visual de Italia. ¿Quién sabe si no resonará este ejemplo en un futuro, en las adquisiciones por parte de la Universidad de Navarra, ya reconocida por los "incunables" que posee, representativos de la fotografía en España?

\section{Ordenación de las colecciones: memoria e investigación}

A lo que voy con la mención de las colecciones más bien genéricas de la fotografía mundial es que su ordenación no se ha hecho hasta época bastante reciente. En España ha ocurrido, por ejemplo, en la Biblioteca Nacional, realizada en 1989 por Isabel Ortega y Gerardo Kurtz, con ocasión de los 150 años de fotografía en la Biblioteca Nacional, la obra faraónica realizada en forma de catálogo, admirado incluso allende las fronteras del país. Ha sido además un reconocimiento del mérito de la investigación y de lo prometedor que puede ser ésta, pese a las muchas personas que siguen utilizando los fondos para constituir, sondear, "probar" y explorar la historia de lugares de España en particular, como es de suponer. Semejante combinación de memoria (de la historia propia) e investigación (de la fotografía como fenómeno artístico y tecnológico perteneciente a la humanidad en general) a mí me parece muy saludable. Y me lo parece menos la reducción del interés a lo primero exclusivamente. En efecto, los italianos tienen una revista que se llama Memoria

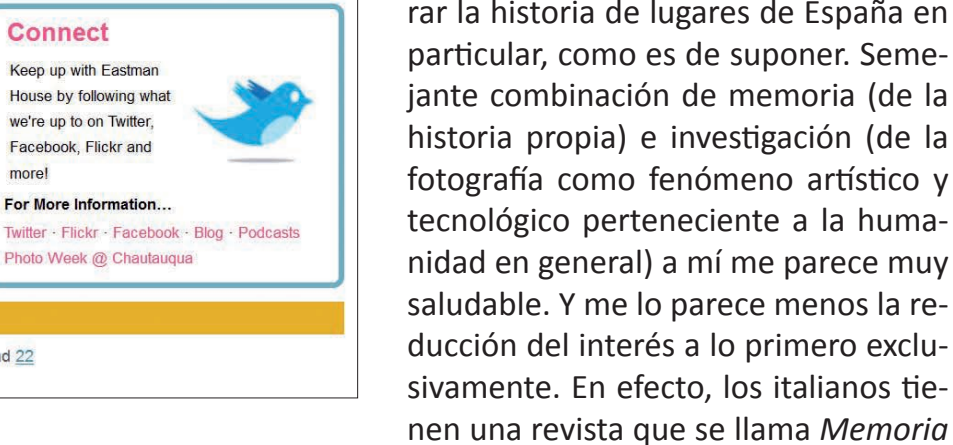

Location : 900 East Avenue, Rochester, NY $14607 \cdot$. More Information · RTS Routes 17, 18/19, 21, and 22

Hours: Tue. Wed. Fri. Sat: $10 \mathrm{am}-5 \mathrm{bm}$. Thu 10am - 80m - Sun: $1 \mathrm{pm}-5 \mathrm{pm}$. More Information

George Eastman House, http://www.eastmanhouse.org
Explore educational resources for recreational learners to For More Information.. Online Colloctions - Notes on Photograph Image Magazine - Workshops · Discovery Kits For More Information.. Make a Donation - Join - Rone Eastman House Shop - Image Licensin

witter - Flickr - Facebook - Blog - Podc hoto Week@ Chautauqua 
e ricerca que representa las dos facetas, y celebraría que hubiese esfuerzos parecidos en muchos países. De hecho, muchos números de la ya mencionada History of photography representaban semejante aproximación a los fondos de fotografía antigua.

La ordenación de los archivos fotográficos, a pesar de la naturaleza, facilidad, calidad o cantidad de la investigación que latiera en su respectivo trasfondo, no era una exclusividad de los países no españoles. Recuerdo de haber tropezado con experiencias positivas en España ya en 1978. Me vienen a la mente l'Institut d'Estudis Ilerdencs y la antigua Casa de l'Ardiaca (Arcediano) en el Barrio Gótico de Barcelona, fenómenos un tanto sorprendentes en aquel entonces.

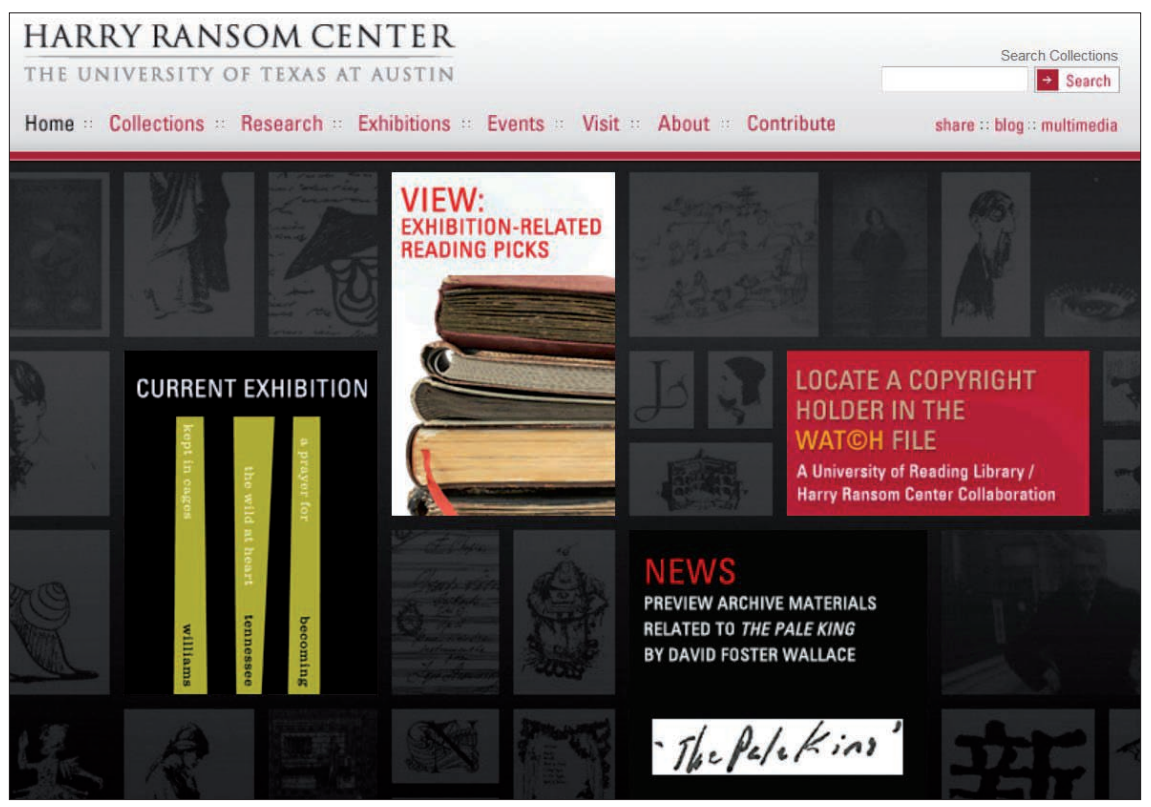

Harry Ransom Humanities Research Center, http://www.hrc.utexas.edu
Sin embargo, en otros países no era siempre así, pues se entreveía por lo general un esfuerzo por ordenar con intención de hacer destacar la autoría (y metodología y tecnología) de la fotografía o su ubicación dentro de la perspectiva de la fotohistoria -término casi desconocido entonces- cuya perspectiva se iba haciendo, como bien se podría apreciar poco después, amplísima, hasta infinita.

Este modo de comprender unos fondos fotográficos beneficiaba más al historiador de la fotografía que al historiador del lugar, y esta observación es crucial para comprender un aspecto importante de los presentes comentarios. A saber, se entiende perfectamente que un instituto de estudios sobre Lleida se organice por temas locales, y se entiende que la antigua Casa de l'Ardiaca de Barcelona lo haga según los momentos significativos para la historia de allí. No obstante la organización que representaban estos ejemplos, no ayudaba gran cosa en la formulación de una historia de la fotografía como hecho tecnológico, artístico o socio-cultural.

Sin embargo, cuando existían escasísimas colecciones fotográficas que tuvieran en cuenta ambos enfoques -tres o cuatro "grandes" y un manojo de otras- tampoco se había manifestado el interés intelectual o la necesidad de la investigación en la fotohistoria. Eso hubiera hecho que poco a poco los fondos se hubieran ido organizando para posibilitar la fácil producción de estudios de comunicación y arte, no sólo la historia de lugares.

Por experiencia propia puedo afirmar que la cuantiosa compra de la llamada Colección Gernsheim por parte del estado de Texas se quedó almacenada en un espacio reducido (por no decir en un armario grande) durante aproximadamente un lustro, antes de que se construyera el que se conoce ahora como el famoso Harry Ransom Humanities Research Center. Ni hablar de ordenación de la colección, pues no había manera práctica de hacerlo. $Y$ aun dentro de las colecciones en las que existía algún criterio tras su almacenaje faltaba camino por andar antes de que al buscar "España", por citar un ejemplo, se hallaran todos los materiales existentes para una investigación en su fotohistoria.
En lo que concierne a España, los fondos del Victoria \& Albert Museum carecían de suficientes conocimientos iconográficos y -no menos importante- de autoría. Es decir, aun en un gran centro donde definitivamente no se minimizaba el aspecto artístico y de autoría en comparación con el elemento localista, faltaba bastante que hacer en ese aspecto. Mientras tanto, los fondos más o menos organizados con propósito de suministrar cierto tipo de documentación identificación de obras de arte, por ejemplo, a lo que se dedicaba el Courtauld Institute of Art de Londres- aunque no se limitaran a lo regional o nacional, no estaban ordenados para el estudio de la fotografía, sino más bien de la realidad representada en la foto.

La investigación en fotografía antigua como totalidad sociopolítica, y no sólo por las imágenes fotográficas que representan algo (precisamente porque en general interesa más la realidad que representan que el objeto fotográfico mismo), ha sido promocionada por las historias que se han escrito sobre la fotografía misma, y por los autores que han enseñado cómo se puede escribir crítica de la fotografía. Fuera por razones histórico-económicas, fuera por otras más bien psicológicas, España no se preocupó por la ordenación de sus fondos fotográficos hasta varios años más tarde que otros países, pero esto no ha representado un retraso muy grave. Sin embargo, debido a la influencia de su estructura gubernamental autonómica, el remover y ordenar fondos ha puesto el énfasis en la realidad local o regional que representa la fotografía, muchísimo más que en la fotografía antigua como totalidad socio-política.

\section{Mi trabajo como investigador en España y sobre España}

He puesto tanto énfasis en esto de las colecciones puestas al servicio del historiador de la fotografía misma, porque deseaba hacer constar que por lo general no me he dedicado a la historia de los lugares y (menos) al uso de la imagen para ilustrarlas. Más bien he intentado tener una visión global y crítica de la fotografía y del objeto fotográfico. 
En los años en que comencé mis trabajos, en España se ponían obstáculos a la investigación si ésta tenía relación con la Guerra civil, sobre todo a los extranjeros. Como no me interesaba en un principio investigar la fotohistoria de España posterior a 1910 ó 1915, ya de entrada anunciaba en qué momento de la historia acababa mi interés, lo que solía calmar sospechas de cualquier motivo que tuviera que ver con la Guerra. Evidentemente, este tipo de aproximación al tema era totalmente innecesario en el resto del mundo. Es una anécdota que menciono sólo para no dejar preguntas en el aire, y porque reconozco que es natural que a un joven investigador de la actualidad ni se le ocurriría el detalle; o por lo menos no se imaginaría que existiera tal grado de restricción y, por consiguiente, tal grado de "diplomacia" que uno tuviera que ejercer sólo para poder pisar un archivo, tanto privado como institucional.

\section{En la cultura o en la psyche de España me pareció ver arraigado que no se ad- mitía la intervención desde fuera}

Pero a pesar de lo anormal que le parezca al joven investigador este procedimiento, absolutamente necesario a lo largo de los 1970 como mínimo (es decir, aun después de la muerte de Franco), había siempre otros factores que dificultaban la investigación en muchos fondos de España en comparación con el resto de los países a los que me he referido. $Y$ creo que en este punto debería enfocarse una parte notable de mi atención al asesorar estas experiencias. Me refiero a algo que a mí me pareció ver arraigado en la cultura o en la "psyche" de España: no se admitía la intervención, sobre todo la intervención desde fuera. Yo lo entendía muy bien, porque confieso ser oriundo de la zona de Estados Unidos más aferrada a la estructura social a base de aldeas; rincones geográficos que protegen lo suyo como si de ello dependiera su misma existencia. $Y$ en los casos raros en los que sí admiten intervención desde fuera, el interventor goza de la protección de que se benefician los aldeanos de por vida, aun cuando -y aquí viene el pecado- esa protección escondiera la cosa más reprobable: una auto-defensa difícil de comprender, tanto desde dentro como desde fuera, y posiblemente más desde dentro, pero por ello tanto más aferrada. Desde fuera no se entiende qué es lo que hay que defender, y desde dentro a lo mejor se intuye el qué, pero no se indaga en su naturaleza.

Cabía la posibilidad de que yo perdiese el tiempo mientras andaba en busca del tiempo perdido. Sin embargo, el empuje que manifestaban los de fuera de España, que se interesaban en la fotohistoria, mi propia obsesión con las tecnologías del XIX español sobre todo con respecto a su quehacer literario en todas sus manifestaciones, y la curiosidad por parte de algunos españoles por el bicho raro que iba en busca de datos tan extraños, me impulsaban a seguir adelante y a todo vapor, pese a los obstáculos que se ponían en el camino.

Por cierto, había personas en España que intuían bastante bien -por los motivos que fueran- que si lograba mi objetivo habría sumado a toda una rama del saber que latía en potencia pero que no se había definido. España sería capaz de afirmar que el fenómeno fotográfico se dio también en el país, aunque de momento no se viera. Pienso primeramente en el editor Santiago Saavedra (Ed. El Viso), muy consciente de esta laguna en la historia del arte de España, y en cantidad de españoles que me abrieron las puertas a sus fondos privados: Iñaki Aguirre-Franco, Nicolau Puig, Carlos Durán-Torrens, Miquel Porter-Moix, Manuel Coyne, José Pettenghi-Estrada, José-Joaquín Arazuri-Díez, Nicolás Sobrino-Fernández, José García-Tojo, entre otros. Me parecía que ponían una fe incuestionable en lo que yo había emprendido, o por lo menos en lo que esto prometía si resultaba.

Aún más sorprendente tal vez fue que varios directores de fondos institucionales parecieran intuir que esto tenía que realizarse; que en el proceso de su realización a lo mejor se sacaba algún beneficio para los fondos respectivos que ellos representaban. Fernando Delgado del Museo Municipal de Madrid, Elena Páez-Ríos y Elena Santiago-Páez de la Biblioteca Nacional de España y Pere Voltes-Bou de la Casa de I'Ardiaca barcelonesa, fueron algunos de los que representaron dicha toma de conciencia institucional.

Los centros extranjeros mostraban otro motivo un poco diferente al de España, que les impulsaba a facilitarme entrada a sus fondos. La categoría "España" era en muchas instituciones un elemento oculto en misterios: iconográficos (es decir, de contenido representado), biográficos, sociales, económicos, etc. El Getty me invitó a asesorar y organizar algunos de sus fondos sobre España, y en numerosas ocasiones trabajé en los fondos del Harry Ransom Humanities Research Center de Texas, una vez en la New York Public Library, otra en la Eastman House de Rochester, sin contar varias universidades en Estados Unidos, donde hice investigaciones por el estilo. Dos veces fui invitado a trabajar en los fondos "españoles" del Centre Canadien d'Architecture (Montréal) -luego haré más comentarios sobre este lugar al mencionar algunos aspectos metodológicos y técnicos de investigación-.

En muchos centros extranjeros la categoría 'España' era un elemento oculto en todo tipo de misterios

Sin duda el Victoria \& Albert Museum ha sido el centro de más actividad investigadora por mi parte a lo largo de los últimos casi treinta años. Este Museo reconoció, como sucedió también en la Biblioteca Nacional de España y en mi entonces Universidad de Texas (lo que era de suponer), que la participación investigadora en todo detalle de sus fondos -hasta en los registros manuscritos originales del museo, y en las memorias manuscritas que posee el mismo, no sólo en los fondos fotográficos- les iba a rendir un beneficio extraordinario, mientras a mí me significaba la realización de varios libros que he escrito (los de tema Clifford, en parte, y también el de tema Napper/Frith, y en su totalidad el de tema Thurston Thompson). Tampoco he acabado con estos recursos. Pero como pasaba en tantos otros sitios con los fondos relativos a España, a los del Victoria \& Albert Mu- 


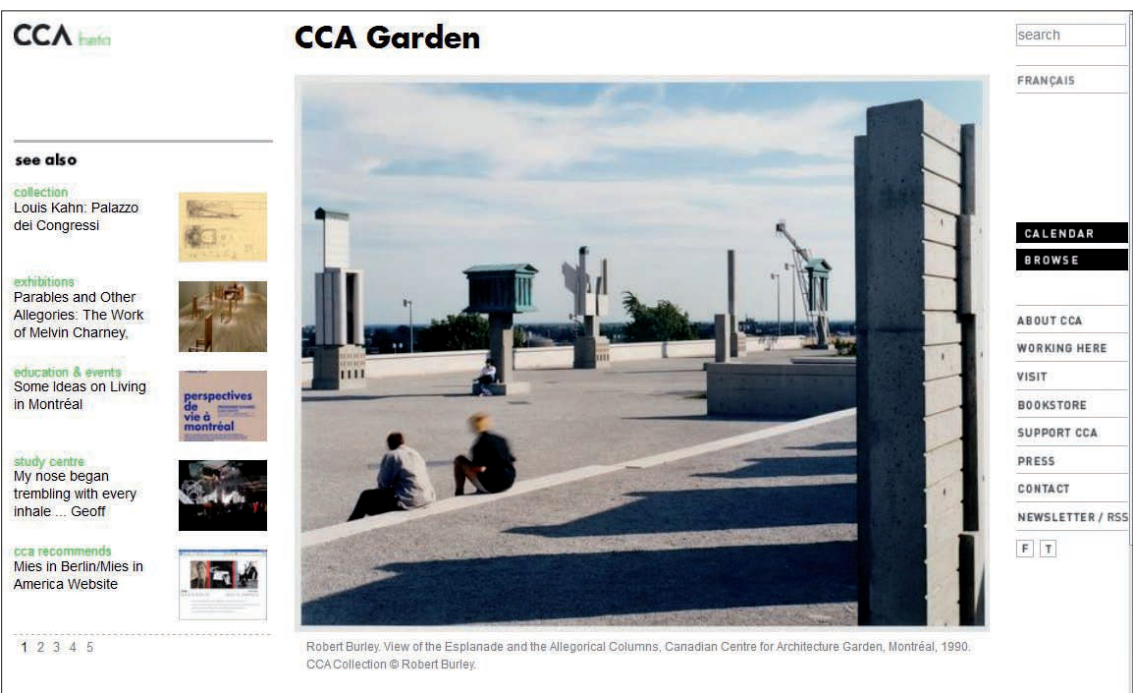

Vista de la explanada y las columnas alegóricas, jardín del Canadian Centre for Architecture, Montréal, 1990. CCA Collection (C Robert Burley. http://www.cca.qc.ca/en/collection/300-cca-garden misma investigación, me gustaría ver que se institucionalizara la formación en conservación, tal como se ha hecho en la Eastman House.

En cuanto a sus respectivos armazones tecnológicos, las colecciones dentro de España están hoy como nunca hubiera imaginado cuando comencé mis investigaciones en la fotografía de España. Aunque no esté yo personalmente de acuerdo con los criterios de categorización en todos los sitios -y no lo estoy debido a que creo que un gran porcentaje de ellos deberían organizarse según las necesidades de la investigación en la historia de la fotografía, como opuesto a la historia de los lugares geográficos- es innegable que la metodología de los archivos y fondos está seum les faltaba organización, identificación e información de toda índole. En fin, les faltaba cierta razón a su existencia. La llamada del Getty para que me trasladara a sus fondos por unos días fue precisamente con este propósito, así como el de mi primera visita a Montréal y a su Centre Canadien d'Architecture.

Nada parecido me pasó nunca en España. En cambio sí me pasó a gran escala en Escocia, cuando la Carnegie Foundation me honró con un nombramiento que sólo otorga una vez cada tres años, y sólo a una persona. Durante la primavera de 2009, aparte de dar conferencias por toda Escocia (así como en Oxford y en el Victoria \& Albert Museum), ayudé en algunos archivos, bibliotecas y museos a identificar fondos con temas de España (mis investigaciones actuales sobre la fotohistoria española incluyen también archivos en Irlanda y Suecia).

\section{Tecnologías y preservación}

En su día, mediados de los 80 -llevo muchos años sin estar en él- el Centre Canadien d'Architecture me pareció una maravilla de organización: que hubieran pensado cómo necesitaban almacenar sus objetos, qué tecnología hacía falta para que cupieran y estuvieran no sólo bien guardados sino también accesibles. Habían logrado una perfecta metodología de almacenaje. Hoy, lo mismo se puede decir de muchos sitios, incluso de muchos en España. Es curioso que hoy, con las restricciones que se imponen por razones de conservación y mantenimiento, los objetos fotográficos de las colecciones sean más accesibles que en los 70 y principios de los 80 .

Dicho esto, hay que decir además que el factor conservación, que naturalmente ha afectado el estado actual de la cuestión, me parece un campo del que se auto-proclama tener pericia con demasiada frecuencia. Hay que reconocer la gran influencia que ha tenido la Eastman House de Rochester en individuos españoles y, quizá en menor grado, la Bibliothèque Nationale en París, pero lo que pudiera y debiera ser todo un campo de formación institucional es hoy más bien un campo en manos de unos pocos que se han aprovechado de los factores oferta y demanda. Aunque de vez en cuando eso puede introducir alguna que otra dificultad a la lejos de donde estaba hace un tercio de siglo.

\section{Colofón}

Aprovecho la ocasión para lanzar un comentario que no he hecho nunca por escrito. Mis investigaciones, excepto durante once meses, han sido pagadas de mi bolsillo. He oído comentar indirectamente de vez en cuando y hasta muy recientemente la letanía del "extranjero rico quien por eso ha podido realizar los trabajos que ha hecho". Sin extenderme más, cualquier español que haya trabajado a mi lado bien sabe que la realidad es contraria a esta imagen. Mis investigaciones a lo largo de un tercio de siglo han sido 95\% por mi propia cuenta, por curiosidad intelectual y, más que nada, porque he tenido la idea -espero que no haya sido pura ilusión- de estar aportando un importante cuerpo de informaciones a un país que, por lo menos en años anteriores, carecía de ellas, su propia fotohistoria, que, si alguien supiera proveerle el armazón, definirla, rellenarla por lo menos mínimamente y luego iluminarla, acabaría rindiendo un provecho cultural de mucho mérito a un gran público. Creo sinceramente que el sueño se ha realizado, y que este público se ha ampliado notablemente.

\section{Webs de algunos lugares citados}

Biblioteca Nacional de España, Madrid http://ww.bne.es/es/Colecciones/Fotografias

Centre Canadien d’Architecture, Montréal http://www.cca.qc.ca

Courtauld Institute of Art, Londres http://www.courtauld.ac.uk

Fondo Fotográfico de la Universidad de Navarra, Pamplona http://www.unav.es/fff

George Eastman House, Rochester, EUA http://www.eastmanhouse.org

Harry Ransom Humanities Research Center, Austin, Texas http://www.hrc.utexas.edu

Victoria \& Albert Museum, Londres

http://www.vam.ac.uk 